\title{
Tingkatan Literasi Sains Mahasiswa Calon Guru Fisika
}

\author{
Siti Nurdianti Muhajir, Putri Rahmalia Lestari, Nenden Sri Rahayu \\ Program Studi Pendidikan Fisika Universitas Garut
}

\begin{abstract}
Abstrak
Masyarakat saat ini berada di era revolusi industri 4.0 yang menitikberatkan pada kolaborasi antara teknologi cyber dan teknologi otomatisasi. Agar masyarakat survie di era ini tentu, saja masyarakat perlu memiliki literate terhadap sains dan maupun teknologi yang merupakan produk sains. Penelitian ini bertujuan untuk menganalisis tingkatan literasi sains mahasiswa calon guru setelah di berikan perlakuan berupa problem solving laboratory pada mata kuliah fisika dasar 2. Penelitian ini merupakan penelitian eksperimental dengan desain one group pretest-posttest design. Hasil penelitian menunjukan terdapat perubahan sebaran kategori literasi sains mahasiswa setelah diberikan perlakuan berupa problem solving laboboratory.
\end{abstract}

Kata kunci: literasi sains; mahasiswa;

\section{Pendahuluan}

Abad 21 adalah era perkembangan ilmu pengetahuan semakin cepat seiring dengan era revolusi industri (Khair, 2021). Era abad ke 21 ini tentunya sangat berpengaruh terhadap berbagai aspek, mulai dari aspek ekonomi, pendidikan, pengetahuan, teknologi dan bahkan informasi. Semua lapisan masyarakat perlu menyadari akan perubahan yang tidak dapat di hindari. Mudah nya akses informasi menjadi salah satu keuntungan juga kerugian bagi masyarakat. Untuk survive di abad ke 21 ini maka masyarakat perlu memiliki kemampuan yang baik untuk memilih dan memilah informasi dan juga menggunakan ilmu pengetahuan yang sesuai untuk memecahkan permasalahan yang di hadapi. Dalam dunia pendidikan institusi perlu mempertimbangkan kompetensi lulusan untuk membekali lulusan agar dapat beradaptasi di abad 21 (Muhajir, 2018). Masyarakat perlu memiliki kemampuan untuk terlibat dalam berbagai hal sehingga dapat mengambil keputusan yang bijak dalam memecahkan masalahnya. Kemampuan untuk terlibat dalam masalah-masalah sains dan eflektif terhadap teknologi merupakan contoh masyarakat yang memiliki literasi sains yang baik. 
Menurut Hurd (1998) literasi sains merupakan sebuah kompetensi yang diperlukan masyarakat untuk berpikir secara rasional tentang sains yang berkaitan dengan masalah pribadi, sosial, politik, ekonomi, dan masalah lain yang ditemui dalam hidup. Adapun literasi sains menurut PISA (2012) adalah kemampuan menggunakan kemampuan sains, mengidentifikasi pertanyaan, menarik kesimpulan berdasarkan bukti dalam rangka memahami serta membuat keputusan berkenaan dengan alam dan perubahan yang dilakukan terhadap alam melalui aktifitas manusia. Fives (2014) mengklasifikasikan literasi sains kedalam beberapa komponen yaitu: peran sains, pemikiran dan kegiatan ilmiah, sains dan masyarakat, matematika dalam sains, serta motivasi dan keyakinan sains. Selain Fives, Beybee (2009) pun mengkategorikan literasi sains kedalam beberapa tingkatan yaitu nominal, konseptual, fungsional, dan multidimensional.

Literasi sains merupakan kemampuan yang perlu dilatihkan kepada siswa, maka sebaiknya para pendidik atau guru juga memiliki literasi sains yang baik sehingga dapat memberikan pengalaman belajar yang meningkatkan literasi sains pada siswa. Berdasarkan hasil studi kasus didapatkan data bahwa kemampuan mahasiswa calon guru fisika memiliki tingkat literasi yang rendah, dalam hal ini hanya berada pada tingkatan nominal saja, padahal idealnya calon guru memiliki literasi sains yang baik agar di kemudian hari ketika terjun menjadi guru mereka dapat menghantarkan peserta didik untuk memiliki literasi sains yang baik sesuai tuntutan zaman. Karena permasalahan ini maka dianggap perlu dan penting untuk meningkatkan kategori literasi sains mahasiswa.

\section{$2 \quad$ Metodologi}

Penelitian ini dilaksanakan di salah satu Universitas di Bandung, metode penelitian yang digunakan pada penenelitian adalah metode pre-experimental design yang dilakukan pada kelas eksperimen saja. Adapun desain yang digunakan pada penelitian ini adalah one group pretest-posttest design (Gregar, 1994). Representasi desain pretest-posttest control group design seperti dijelaskan oleh Sugiyono (2014) diperlihatkan dalam tabel berikut ini:

Tabel 1. Representasi desain pretest-posttest control group design

\begin{tabular}{ccc} 
Pretest & Treatment & Posttest \\
\hline $\mathrm{O}_{1}$ & $\mathrm{X}_{1}$ & $\mathrm{O}_{2}$ \\
\hline
\end{tabular}

Keterangan:

$\mathrm{O}_{1}:$ pretest (sebelum diberi perlakuan)

$\mathrm{O}_{2}$ : posttest (setelah diberi perlakuan)

$\mathrm{X}_{1}$ : Perlakuan (treatment), yaitu implementasi model problem solving laboratory

Sampel dalam penelitian ini diberi perlakuan berupa problem solving laboratory selama tiga kali pertemuan. Sampel diberi pretest untuk mengetahui kemampuan 
awal literasi sains, dan posttest setelah diberikan perlakuan berupa model problem solving laboratory. Hasil jawaban pretest dan posttest dianalisis untuk melihat gambaran tingkatan literasi sains mahasiswa sebelum dan sesudah perlakuan. Analisis tingkatan literasi sains ini disesuaikan dengan kategori literasi sains (Bybee, 2009) yaitu nominal, konseptual, fungsional, dan multidimensional. Penjelasan setiap kategori disajikan pada tabel 2 berikut:

Tabel 2. Kategori jawaban berdasarkan literasi sains (Soobard \& Rannikmae, 2011)

\begin{tabular}{|c|c|}
\hline Kategori & Deskripsi \\
\hline Nominal & $\begin{array}{l}\text { Menyetujui pendapat orang lain tanpa melibatkan } \\
\text { pemikiran sendiri disertai dengan penulisan konsep } \\
\text { yang belum mampu dibenarkan atau mengalami } \\
\text { kesalahan dalam memahami suatu konsep. }\end{array}$ \\
\hline Fungsional & $\begin{array}{l}\text { Belum mampu membuat hubungan antar konsep karena } \\
\text { keterbatasan informasi yang dimiliki sehingga tidak } \\
\text { mampu memberikan pendapat terkait fenomena yang } \\
\text { disajikan. }\end{array}$ \\
\hline $\begin{array}{l}\text { Konseptual/ } \\
\text { Prosedural }\end{array}$ & $\begin{array}{l}\text { Memahami hubungan antar konsep sehingga mampu } \\
\text { menganalisis dan memberikan solusi terkait masalah } \\
\text { yang diberikan. }\end{array}$ \\
\hline Multidimensional & $\begin{array}{l}\text { Mampu mengaplikasikan pemahaman yang didapat dari } \\
\text { hubungan antar konsep dengan kejadian yang dialami } \\
\text { setiap hari. }\end{array}$ \\
\hline
\end{tabular}

\section{Hasil dan Pembahasan}

Berdasarkan hasil analisis diketahui bahwa literasi sains awal mahasiswa sebelum diberi treatment berupa model problem solving laboratory sebagaian besar berada pada tingkatan nominal dengan persentase rata-rata $76,9 \%$, hal ini terlihat dari jawaban mahasiswa yang singkat. Dari 10 soal yang diberikan mahasiswa hanya menjawab empat sampai sepuluh soal dengan jawaban yang sebagian besar salah. Selain berada pada tingkatan nominal beberapa mahasiswa memiliki kemampuan literasi pada tingkat fungsional dengan persentase rata-rata yaitu sebesar $11 \%$, pada tingkatan fungsional ini mahasiswa dapat mengingat fakta-fakta dasar tetapi tidak dapat menggambarkan hubungan konsep dengan konsep lain. Adapun persentase rata-rata untuk mahasiswa yang tidak menjawab adalah sebesar 23,7\%. Grafik hasil analisis persentase rata-rata jawaban pretest mahasiswa menurut tingkat literasi sains di sajikan pada gambar 1 . 


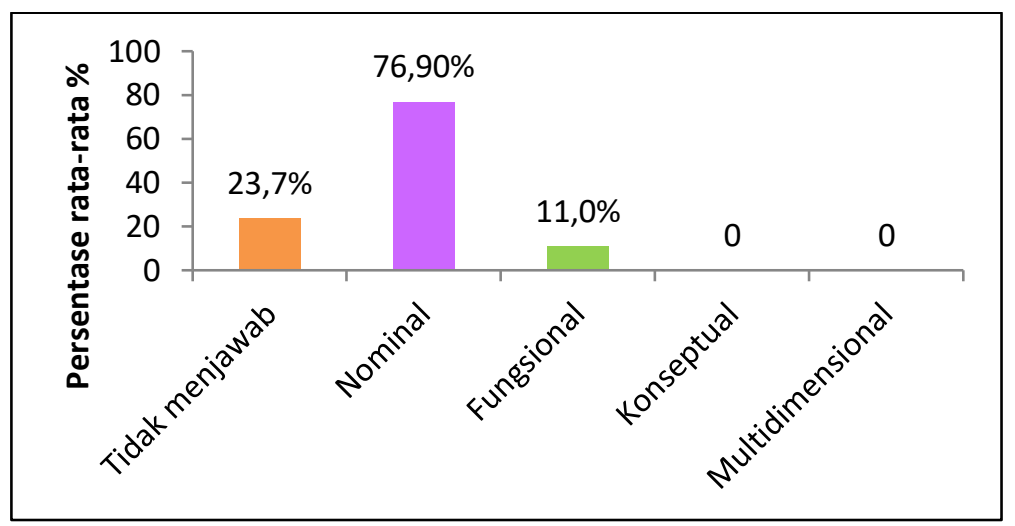

Gambar 1. Presentase rata-rata jawaban pretest menurut kategori literasi sains

Berdasarkan gambar 1 tingkatan literasi terbanyak mahasiswa berada pada kategori nominal, pada kategori ini mahasiswa cenderung mengalami miskonsepsi (Mutasam, U., Ibrohim, I., \& Susilo, H. 2020). Mahasiswa hanya dapat menuliskan istilah ilmiah, namun tidak berada pada kondisi dapat membenarkan istilah tersebut, hal yang diketahui mahasiswa hanya berupa pemahaman yang minimal (Braaten \& Windschitl, 2011; Campbell, et al., 2013). Mahasiwa yang berada pada tingkatan ini umumnya memiliki naive theories (Shofiyah, N. 2015). Hal ini diduga karena mahasiswa tidak terbiasa untuk memecahkan masalah dengan terlibat langsung dan membaca berbagai sumber. Mahasiswa tidak mendapatkan pengalaman belajar yang nyata sehingga konsep materi yang dipahami oleh mahasiswa tidak maksimal.

Hasil analisis jawaban posttest mahasiswa disajikan pada Gambar 2. Hasil analisis diperoleh data bahwa mahasiswa memiliki tingkatan literasi sains yang lebih beragam dibanding sebelum diberikan treatment berupa problem solving laboratory. Untuk jawaban posttest ini literasi sains mahasiswa tingkat nominal persentase ratarata nya adalah sebesar $33,3 \%$. Sedangkan persentase rata-rata untuk tingkat fungsional sebesar $28,3 \%$, untuk tingkat konseptual persentase rata-rata nya adalah $24,2 \%$ dan untuk tingkat multidimensional persentase rata-ratanya sebesar $29 \%$. Persentase rata-rata tertinggi adalah pada tingkat nominal sedangkan persentase ratarata terendah adalah pada tingkat konseptual atau prosedural yakni sebesar 24,4\%. Hal ini karena mahasiswa masih harus diberi instruksi untuk membaca dan mencari sumber informasi, mahasiswa umumnya harus didorong dengan diberi tugas agar mau membaca, tanpa adanya tugas sebagian besar mahasiswa tidak akan mencari informasi dan membaca literatur. Hal ini diduga adalah alasan mengapa tingkatan kemampuan literasi sains mahasiswa berbeda. Untuk yang membaca lebih banyak sumber, umumnya memiliki kemampuan literasi dengan tingkatan lebih tinggi dibanding dengan yang hanya membaca satu sumber. Hal ini tentu saja menarik untuk diteliti lebih lanjut. Gambar 2 adalah grafik persentase rata-rata jawaban posttest mahasiswa menurut tingkat literasi sains. 


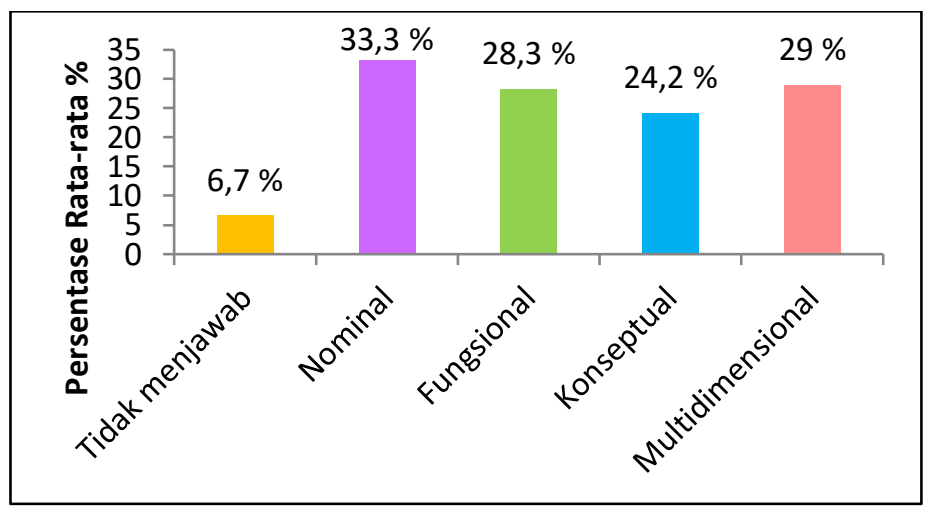

Gambar 2. Presentase rata-rata jawaban posttset menurut kategori literasi sains

Keragaman kategori literasi sians mahasiswa di sebabkan oleh perlakuan berupa problem solving laboratory, Hal ini tentu saja sesuai dengan pendapat Toharudin (2011) menyatakan dalam bukunya Literasi Sains Peserta Didik menjelaskan bahwa problem solving adalah salah satu model yang membangun lierasi sains peserta didik, hal ini diperkuat oleh penelitian Rakhmawan dalam Rahmatunnisa (2014) menjelaskan bahwa kegiatan laboratorium berbasis inkuiri dapat meningkatkan literasi sains siswa SMA. Hal ini diperkuat oleh penelitian Wen (2020) yang menyatakan aktifitas inkuiri dapat membantu melatihkan literasi sains. Pembelajaran berbasis laboratorium efektif untuk mendorong mahasiswa dalam memecahkan masalah dengan membaca berbagai sumber relevan. Adapun Ahmada (2021) menyatakan literasi sains dapat dilatihkan dengan kegiatan pembelajaran yang menuntut pemikiran mendalam seperti pemecahan masalah, percobaan, projek dan juga STEM.

\section{$4 \quad$ Kesimpulan}

Berdasarkan hasil penelitian dan analisis data, diperoleh kesimpulan bahwa kemampuan awal literasi sains mahasiswa pendidikan fisika sebagian besar berada pada kategori nominal, kemudian setelah di berikan perlakuan berupa problem solving labroratory mahasiswa memiliki tingkat literasi sains yang lebih beragam.

\section{Daftar Pustaka}

Ahmada, R. F., Suwono, H., \& Fachrunnisa, R. (2021, March). Development scientific literacy through STEM project in biology classroom: A mixed method analysis. In AIP Conference Proceedings (Vol. 2330, No. 1, p. 030020). AIP Publishing LLC. 
Braaten, M., \& Windschitl, M. (2011). Working Toward a Stronger Conceptualization of Scientific Explanation for Science

Bybee, R., McCrae, B., \& Laurie, R. (2009). PISA 2006: An Assessment of Scientific Literacy. Journal of Research in Science Teaching, 46(8), 865883. https://doi.org/10.1002/tea.20333

Campbell, T., Longhurst, M., Duffy, A. M., Wolf, P. G., \& Shelton, B. E. (2013). Science Teaching Orientations and Technology-Enhanced Tools for Student Learning. Research in Science Education, 43(5), 2035-2057. https://doi.org/10.1007/s11165-012-9342-x

E Ashari, S. E., \& Wisanti, W. (2021). Kelayakan Teoretis Lembar Kegiatan Peserta Didik (LKPD) Lumut Berbasis Literasi Sains untuk Melatihkan Keterampilan Berpikir Kritis Peserta Didik. Berkala Ilmiah Pendidikan Biologi (BioEdu), 10(1), 95-101.

Fives, H., Huebner, W., Birnbaum, A. S., \& Nicolich, M. (2014). Developing a measure of scientific literacy for middle school students. Science Education, 98(4), 549-580.

Gregar, J. (1994). Research Design (Qualitative, Quantitative and Mixed Methods Approaches). Book published by SAGE Publications, 228.

Hurd, P. D. (1998). Scientific literacy: New minds for a changing world. Science education, 82(3), 407-416.

Khair, B. N., Astria, F. P., Wardani, K. S. K., Nurwahidah, N., \& Sriwarthini, N. N. (2021). Pengembangan LKPD Literasi Sains Berbasis Lesson Study for Learning Community (LSLC). Jurnal Pijar Mipa, 16(1), 136-141.

Muhajir, S. N. (2018). PENERAPAN PROJECT ORIENTED PROBLEM BASED LEARNING DENGAN READING INFUSION UNTUK MELATIHKAN KETERAMPILAN ABAD KE 21 MAHASISWA (Doctoral dissertation, Universitas Pendidikan Indonesia).

Muhajir, S. N., Mahen, E. C. S., Yuningsih, E. K., \& Rochman, C. (2015). Implementasi model problem solving laboratory untuk meningkatkan kemampuan literasi sains mahasiswa pada mata kuliah fisika dasar II. Disajikan dalam Simposium Nasional Inovasi dan Pembelajaran Sains. Bandung.

Mutasam, U., Ibrohim, I., \& Susilo, H. (2020). Penerapan Pembelajaran Sains Berbasis Inquiry Based Learning Terintegrasi Nature of Science Terhadap Literasi Sains. Jurnal Pendidikan: Teori, Penelitian, dan Pengembangan, 5(10), 1467-1472. 
Rakhmawan, Aditiya. 2012. Kegiatan Laboratorium Berbasis Inkuiri pada Submateri Pokok Sel Volta untuk Meningkatkan Literasi Sains Siswa SMA. Jurnal Pendidikan Kimia. Tersedia online pada http://file.upi.edu/direktori/tesis.pendidikankimia/. Diunduh tanggal 3 Maret 2015. Pukul 05.30 WIB.

Shofiyah, N. (2015). Deskripsi literasi sains awal mahasiswa pendidikan IPA pada konsep IPA. PEDAGOGIA: Jurnal Pendidikan, 4(2), 113-120.

Soobard, R., \& Rannikmae, M. (2011). Assessing Student's Level of Scientific Literacy Using Interdisciplinary Scenarios. Science Education International, 22(2), 133-144.

Sugiyono. (2014). Metode Penelitian Pendidikan:Pendekatan Kuantitatif, Kualitatif, dan $R \& D$ Bandung: Alfabeta.

Toharudin, Uus. (2011) Membangun Literasi Sains Peserta Didik. Bandung: Humaniora

Wen, C. T., Liu, C. C., Chang, H. Y., Chang, C. J., Chang, M. H., Chiang, S. H. F., ... \& Hwang, F. K. (2020). Students' guided inquiry with simulation and its relation to school science achievement and scientific literacy. Computers \& Education, 149, 103830. 